\title{
Retinoid metabolism in the rat small intestine
}

\author{
Simmy Thomas, Ramamoorthy Prabhu and Kunissery A. Balasubramanian* \\ The Wellcome Trust Research Laboratory, Department of Gastrointestinal Sciences, Christian Medical College, \\ Vellore-632004, India
}

(Received 1 April 2004 - Revised 27 July 2004 - Accepted 21 September 2004)

\begin{abstract}
Vitamin A (retinol) is essential for epithelial cell growth, differentiation and proliferation. The absorption of retinol occurs in the small intestine, and the metabolism of this vitamin is not well studied in this organ. The intestinal epithelium has a high rate of cell proliferation and differentiation, and the present study looked at the level of retinoids and metabolizing enzymes involved in their interconversion along the villus-crypt axis under normal conditions. Intestine was removed from control rats, and enterocytes at various stages of maturation and differentiation were quantified by the metal chelation method. Using HPLC, various retinoid concentrations in the cell homogenate and the metabolizing enzymes in the cytosol were quantified. The proliferating crypt cells were found to have a higher level of retinoic acid as well as of the enzymes involved in its formation, such as retinaldehyde oxidase and retinol dehydrogenase, compared with the villus cells, suggesting a possible role for this compound in intestinal epithelial cell proliferation and differentiation. The high level of retinol and high retinaldehyde reductase activity in the villus cells suggest the important role played by this enzyme in the conversion of dietary $\beta$ carotene to retinol via retinaldehyde. In summary, this study has given for the first time a detailed analysis of the retinoid levels and metabolizing enzymes in different cell populations in the rat small intestinal epithelium.
\end{abstract}

Retinol: Retinoic acid: Metabolizing enzymes: Intestine

Vitamin A (retinol) is obtained from the diet mainly as plant carotenoid pigments, primarily $\beta$-carotene. Unlike animals, plants do not contain vitamin $\mathrm{A}$, but many dark green or dark yellow plants contain carotenoids such as $\beta$-carotene, which serve as provitamins that are converted within the intestinal mucosa to retinol during absorption (Herr et al. 1993). Vitamin A is stored in the liver as retinyl esters and, when needed, is exported into the blood, where it is carried by retinol-binding protein for delivery to other tissues. Retinol is the immediate precursor of two important active metabolites: retinaldehyde (retinal), which plays a critical role in vision, and retinoic acid, which serves as an intracellular messenger that affects the transcription of a number of genes (Wald, 1968; Giguere et al. 1987). Vitamin A is involved in controlling the differentiation and proliferation of various epithelia in the body (Rexer et al. 2001). An absence of vitamin A can lead to an uncontrolled proliferation of epithelial stem cells that fail to differentiate into the normal phenotype in many lining epithelia. Retinol and its metabolites are essential for growth and cell differentiation, particularly of epithelial tissue (Nau \& Blanner, 1999). These functions are thought to be mediated through the binding of retinoic acid to retinoid nuclear receptors. The retinoid receptors that have been identified include the retinoic acid receptors and retinoid $\mathrm{X}$ receptors (Chambon, 1996).

The epithelial cells (enterocytes) lining the small intestine have a high turnover, this being a finely regulated process extending from undifferentiated crypt stem cells to terminally differentiated villus cells. The villus cells are mainly involved in the digestion and absorption of nutrients. In the normal situation, the movement of cells from the crypt to the villus tip is completed in 2-5 days and terminates in cells being removed by apoptosis and/or exfoliation (Wong et al. 1999). It is known that vitamin A is involved in regulating the proliferation and differentiation of cells. The requirements for this vitamin can be satisfied by consuming either animal food containing vitamin A ester or plant food containing provitamin A carotenoids (Lintig \& Vogt, 2004). The source of retinol in the enterocytes is also likely to be contributed to by retinol delivered from the systemic blood. The conversion of $\beta$-carotene to vitamin $\mathrm{A}$ in the small intestine provides the first evidence that these carotenoids are the direct precursors of vitamin A in animals (Moore, 1930). $\beta$-Carotene in the diet can be converted to two molecules of retinaldehyde in the small intestine by cleavage, specifically at its central double bond, catalysed by $\beta$-carotene, $15,15^{\prime}$-monooxygenase. The retinaldehyde thus formed can further be metabolized to either retinol or retinoic acid by retinaldehyde reductase and retinaldehyde dehydrogenase respectively (Fig. 1) (Napoli, 1999). Inside the enterocyte, retinol is bound to cellular retinol-binding protein II following esterification to retinyl esters by lecithin-retinol acyl transferase. Together with phospholipids, cholesterol and triacylglycerols, the retinyl esters are packed into chylomicrons and released into the lymph for transport to the liver and for further distribution to other tissues (Ong, 1993).

Retinoids are essential for growth and cell differentiation, particularly of epithelial tissue. Restricted availability of retinol 


\section{$\beta$-Carotene}

$\beta$-Carotene15, 15' monooxygenase

2 molecules of retinaldehyde

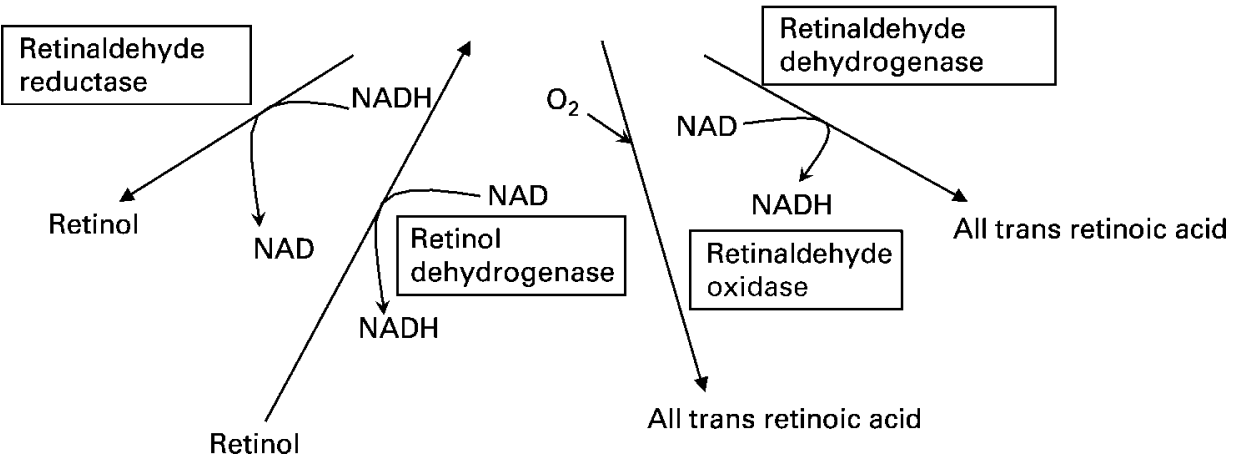

Fig. 1. Pathways of metabolism of vitamin $A$.

(vitamin A) to the intestinal epithelial cells has been shown to result in an impaired control of proliferation in these cells (Deluca \& Roberts, 1969; Parlesak et al. 2000). Although small intestinal enterocytes play a central role in the absorption and metabolism of dietary retinol, very little is known about the actual metabolism of retinoids in the gastrointestinal epithelium. The present study looked at the level of various retinoids in different cell populations of the small intestine and the metabolizing enzymes involved in the interconversion of these retinoids under normal conditions.

\section{Materials and methods}

Bovine serum albumin, ethylene glycol-bis- (B-aminoethyl ether) $\mathrm{N}, \mathrm{N}, \mathrm{N}^{\prime}, \mathrm{N}^{\prime}$-tetraacetic acid, dithiothreitol (DTT), NAD, its reduced form (NADH), all- trans-retinol, all-trans-retinal and all-trans-retinoic acids were obtained from Sigma Chemical Co. (St Louis, MO, USA). All other chemicals used were of analytical grade.

\section{Animals}

Adult Wistar rats of both sexes (200-250 g), exposed to a daily $12 \mathrm{~h}$ light-dark cycle and fed ad libitum water and rat chow (Pranav Agro Industries Ltd., Bangalore, Karnataka, India) were used in this study. The composition of rat chow, as given by the manufacturer, consisted of $21.26 \%$ crude protein, $4.69 \%$ crude oil and $2.96 \%$ crude fibre, with added minerals and vitamins, giving $15.06 \mathrm{MJ} / \mathrm{kg}$ of energy. The normal rats in our experimental set up consumed nearly $40 \mathrm{~g}$ rat chow per day, corresponding to a carotene intake of $3.68 \mathrm{mg}$, and $346 \mu \mathrm{g}$ vitamin A, as measured by HPLC. This study was approved by the institution's Animal Experimentation Ethics Committee.

\section{Isolation of villus and crypt cells from the small intestine}

Care was taken during both cell isolation and retinoid extraction to avoid any light, and all procedures were carried out under dim light. Overnight-fasted rats were killed by decapitation. The abdomen was opened, and the whole length of the small intestine was gently washed with cold physiological saline containing $1 \mathrm{~mm}$ DTT. Enterocytes of various stages of maturation (villus to crypt) were isolated by the metal chelation method as previously described (Weiser, 1973).

Briefly, the intestine was filled with solution A $(1.5 \mathrm{mM} \mathrm{KCl}$, $96 \mathrm{mM} \mathrm{NaCl}, 27 \mathrm{~mm}$ sodium citrate, $8 \mathrm{mM} \mathrm{KH}_{2} \mathrm{PO}_{4}$ and $5.6 \mathrm{~mm}$ $\mathrm{Na}_{2} \mathrm{HPO}_{4}, \mathrm{pH} 7 \cdot 3$ ), clamped at both ends and incubated at $37^{\circ} \mathrm{C}$ for $15 \mathrm{~min}$. Following incubation, the luminal contents of the intestine were discarded, and the intestine was filled with solution B (PBS pH 7.3 containing $1.5 \mathrm{~mm}$ EDTA and $0.5 \mathrm{~mm}$ DTT) and incubated at $37^{\circ} \mathrm{C}$ for different time intervals of $4,2,2,3,4,6$, 7, 10 and $15 \mathrm{~min}$. At the end of each time period, the incubated solution containing cells was collected in separate tubes. These nine fractions were pooled into three, the first three fractions being the villus cells, the next three fractions the middle cells, and the last three fractions the crypt cells. These cell fractions were centrifuged at $900 \mathrm{~g}$ for $5 \mathrm{~min}$ and washed with Krebs-Hensleit buffer $\mathrm{pH} 7.4$ containing $5 \mathrm{~mm}$ glucose and $2.5 \mathrm{~mm}$ calcium. Separated villus, middle and crypt cells were identified by assaying the marker enzyme for differentiation, alkaline phosphatase (Thambidorai \& Bachhawat, 1977). The specific activity of alkaline phosphatase in the isolated villus, middle and crypt cells was 0.232 (SD 0.016), 0.086 (SD 0.006) and 0.008 (SD $0 \cdot 001)$ respectively.

\section{Retinol, retinaldehyde and retinoic acid extraction and quantification by $H P L C$}

The suspended cells were homogenized using PBS at $\mathrm{pH} 7.4$, and the homogenate corresponding to approximately $2 \mathrm{mg}$ protein was mixed with an equal volume of $100 \%$ ethanol and 0.025 times the volume of $0.1 \mathrm{M} \mathrm{HCl}$. Neutral and acidic retinoids were extracted twice with three times the volume of hexane. Extracted fractions were dried under $\mathrm{N}_{2}$ and reconstituted in $100 \%$ ethanol for HPLC separation. Retinoids were separated on a Shim-pack CLC-SIL silica column (Shimadzu Co., Tokyo, Japan) running at $1 \mathrm{ml} / \mathrm{min}$ using the mobile phase (hexane-dioxane-acetic acid, 92:8:0·1 v/v). Retinol, retinaldehyde and retinoic acid were monitored at $350 \mathrm{~nm}$ (Rexer et al. 2001). Quantification was performed by relating the area of the peak to areas obtained by the analysis of 
known quantities of retinoid standards and expressed as ng/mg protein. The recovery of these retinoids by this method was about $85 \%$.

\section{Retinoid-metabolizing enzyme activity measurements}

Subcellular fractionation of various cell populations of enterocytes was carried out by differential centrifugation, and cytosol was prepared. This was used for assaying the enzymes involved in retinoid interconversion. Retinaldehyde dehydrogenase activity was estimated by measuring the retinoic acid formed from retinaldehyde. The reaction mixture consisted of cytosolic protein corresponding to approximately $1 \mathrm{mg}, 100 \mu \mathrm{M}$ NAD and $0.5 \mu \mathrm{M}$ retinaldehyde (in ethanol; final concentration in each case) in a total volume of $0.2 \mathrm{ml}$. This was incubated at $37^{\circ} \mathrm{C}$ for $20 \mathrm{~min}$, and the reaction was stopped by the addition of ethanol, followed by extraction and quantification by HPLC as described above. Cytosolic incubations were also carried out in the absence of NAD to look for retinaldehyde oxidase activity. For retinaldehyde reductase activity, $200 \mu \mathrm{M}$ NADH instead of NAD was added and estimated by measuring the retinol formed from retinaldehyde. Retinol dehydrogenase activity was measured by incubating the cytosolic protein corresponding to approximately $1 \mathrm{mg}$ with $2 \mathrm{~mm}$ NAD and $1 \mu \mathrm{M}$ retinol in a total volume of $0.2 \mathrm{ml}$ at $37^{\circ} \mathrm{C}$ for $20 \mathrm{~min}$; again, the reaction was stopped by adding ethanol (Lampen et al. 2000; Rexer et al. 2001), followed by extraction and quantitation by HPLC as described above. Specific activity was expressed as picomoles of product formed per minute per milligram protein.

\section{Protein estimation}

Protein was estimated by Lowry's method using bovine serum albumin as standard (Lowry et al. 1951).

\section{Statistical analysis}

Data are expressed as means with their standard devations from a minimum of six animals with duplicate estimations. The MannWhitney non-parametric test was used for tests of significance of differences between groups. A probability of $<0.05$ was accepted as significant. Statistical calculations were carried out using SPSS (version 9) software (SPSS Inc. Chicago, IL, USA).

\section{Results}

Retinoid levels in various population of enterocytes lining the small intestine were studied, and it was found that the proliferating crypt cells had a 2-4-fold higher level of retinaldehyde and retinoic acid compared with the villus and middle cells. There was a gradual decrease in retinol concentration from the villus tip cells to the crypt region, with the villus cells showing a higher content of retinol than the middle and crypt cells (Fig. 2(a)-(c)).

The interconversion of various retinoids is brought about by different enzymes (Fig. 1). These enzyme activities were measured in the cytosol from different enterocyte populations. Retinaldehyde reductase, which catalyses the conversion of retinaldehyde to retinol, showed 2-4-fold higher activity in the villus cells than the middle and crypt cells (Fig. 3(a)). The reverse of this reaction, namely the conversion of retinol to retinaldehyde,
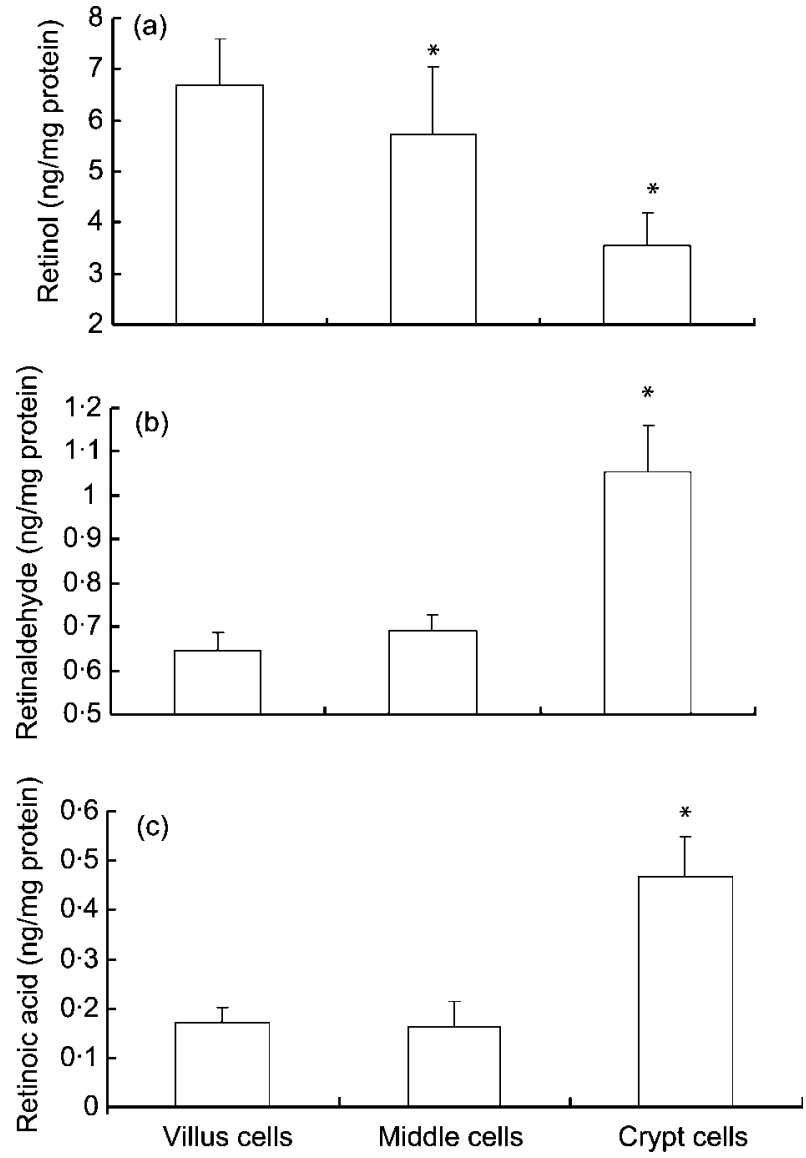

Fig. 2. Retinol (a), retinaldehyde (b) and retinoic acid (c) levels in different cell populations of enterocytes isolated from normal rat intestine. Each value represents the mean with standard devation represented by a vertical bar of six separate experiments $(n 6)$ with duplicate estimations. ${ }^{*} P<0.05 \mathrm{com}$ pared with villus cells.

is catalysed by retinol dehydrogenase, the level of which was found to be higher in the crypt cells than the villus and middle cells (Fig. 3(b)). An increased formation of retinoic acid was seen in the crypt cells, caused by the higher activity of retinaldehyde oxidase or retinaldehyde dehydrogenase, the enzymes responsible for the conversion of retinaldehyde to retinoic acid (Fig. 3(c)). The activity of this enzyme was less in the villus and middle cells. This enzyme activity was independent of NAD in rat enterocytes, suggesting that this enzyme is retinaldehyde oxidase rather than retinaldehyde dehydrogenase.

\section{Discussion}

The intestinal epithelium is a self-renewing monolayer arising from stem cells located at or near the base of the crypts. The integrity and homeostasis of the intestinal mucosa are largely dependent on the continued proliferation, migration and differentiation of the crypt cells (Hanson, 1982). The multipotent stem cells located near the base of each intestinal crypt divide to produce daughter stem cells and more rapidly proliferating transit cells. Transit cells in turn undergo a number of rapid cell divisions and differentiate into mature epithelial cells, migrate to the villus and either die or are extruded into the lumen (Eastwood, 1977). This is reflected by the high turnover of epithelial cells in the intestine. Retinol and its metabolites are known to play an 

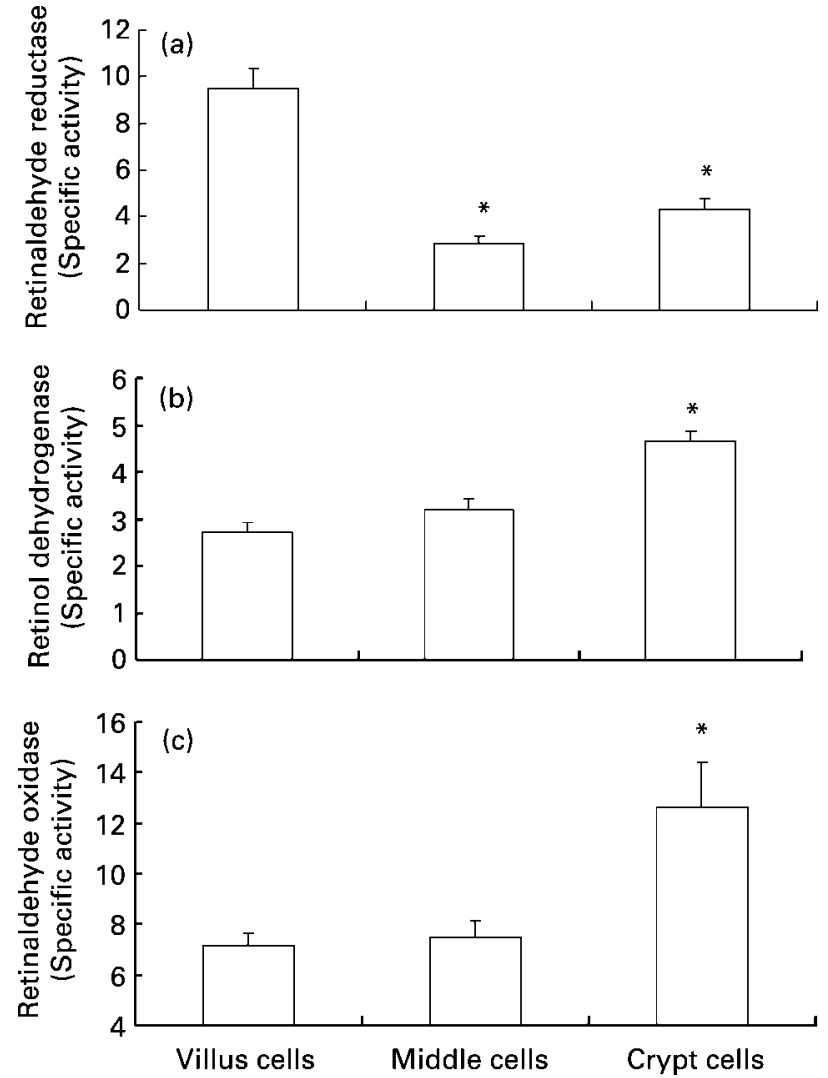

Fig. 3. Retinaldehyde reductase (a), retinol dehydrogenase (b) and retinaldehyde oxidase (c) activity in different cell populations of enterocytes isolated from normal rat intestine. Each value represents the mean with standard deviation represented by a vertical bar of six separate experiments $(n 6)$ with duplicate estimations. ${ }^{\star} P<0.05$ compared with villus cells.

essential role in the development and function of various cells, including digestive tract epithelial cells. Among the metabolites of retinol, retinoic acid is the most active compound and has been shown to play an essential role in cell proliferation and differentiation. (Joseph et al. 1997; Nau \& Blanner, 1999). It was seen that the level of retinoic acid was 3-4-fold higher in proliferating crypt than completely differentiated villus cells. The precursor of retinoic acid, retinaldehyde, was also higher in the crypt cells than other cell populations. The retinol concentration was higher in the villus tip cells, in agreement with their role in vitamin A absorption.

The interconversion of various retinoids is brought about by different enzymes (Fig. 1). The absorption of vitamin A takes place in the villus tip cells, where the maximum conversion of $\beta$-carotene to retinol occurs through the intermediate, retinaldehyde. Retinaldehyde reductase is the enzyme that catalyses the conversion of retinaldehyde to retinol, and the activity of this enzyme was found to be higher in the villus cells than the middle and the crypt cells (Fig. 3(a)). The higher concentration of retinol in the villus tip cells is in agreement with the increased activity of retinaldehyde reductase in these cells. Retinol can be converted to retinaldehyde by the enzyme retinol dehydrogenase, and the activity of this was found to be higher in crypt cells than middle cells. As shown above, the crypt cells also had a higher level of retinaldehyde, which agrees with higher activity of retinol dehydrogenase (Fig. 3(b)). Although the maximum absorption of vitamin A occurs in the villus tip cells, crypt cells may obtain their requirement of vitamin A from the blood, and this may be used for formation of retinoid metabolites.

To understand the physiological role of retinoids in enterocyte proliferation and differentiation, it is crucial to understand the formation of retinoic acid from vitamin $\mathrm{A}$ in the small intestinal enterocytes. The biological function of retinol or retinaldehyde in these cells is mediated by their cytosolic oxidation to all trans-retinoic acid (Wolf, 1984; Blaner \& Olson, 1999), which is an active ligand for retinoic acid receptors (Giguere et al. 1987; Petkovich, 1992). An increased formation of retinoic acid was seen in the crypt cells due to a higher activity of retinaldehyde oxidase or retinaldehyde dehydrogenase, the enzymes responsible for the conversion of retinaldehyde to retinoic acid. Enzyme activity in the presence and absence of NAD was studied, and it was found that the enzyme responsible for this conversion in the rat intestinal epithelium was not NAD dependent, suggesting that this was possibly an aldehyde oxidase. NAD-independent aldehyde oxidase has been shown to play an important role in the formation of retinoic acid (Tomita et al. 1993; Chen et al. 1995; Wojciech et al. 1999). It therefore appears that rat enterocytes have retinaldehyde oxidase rather than retinaldehyde dehydrogenase activity. This enzyme was more active in crypt cells than villus and middle cells (Fig. 3(c)). The formation of retinoic acid has already been shown using total enterocytes (Lampen et al. 2000). Studies have also shown a role for retinoic acid in stimulating early cellular proliferation in the adaptation of the small intestine after partial resection (Wang et al. 1997). Retinoic acid, the physiologically active metabolite of vitamin A, also plays an important role in controlling progression to carcinogenesis in a variety of cancers, including squamous cell carcinoma of the neck, skin cancer and acute promyelocytic leukaemia, and has been used in the treatment of these malignant conditions (Lotan, 1996).

In conclusion, this study has shown for the first time the detailed analysis of the retinoid levels and the metabolizing enzymes in different cell populations of the rat small intestinal epithelium. The proliferating crypt cells were found to have a higher level of retinoic acid as well as of the enzymes involved in its formation, suggesting a possible role for this compound in intestinal epithelial cell proliferation and differentiation. The high level of retinol formation in the villus cells, possibly by the enzyme retinaldehyde reductase, suggests the important role played by this enzyme in the conversion of dietary $\beta$-carotene to retinol via retinaldehyde.

\section{Acknowledgements}

This study was supported by the Wellcome Trust, London and The Council of Scientific and Industrial Research, Government of India. S.T. and R.P. are Senior Research Fellows of the Council of Scientific and Industrial Research.

\section{References}

Blaner WS \& Olson JS (1999) The retinoids: biology, chemistry and medicine. In The Retinoids, 2nd edn, pp. 229-255 [MB Sporn, AB Roberts and DS Goodman, editors]. New York: Raven Press.

Chambon P (1996) A decade of molecular biology of retinoic acid receptors. FASEB J 10, 940-954.

Chen H, Namkung MJ \& Juchau MR (1995) Biotransformation of all- 
trans-retinol and all-trans-retinal to all-trans-retinoic acid in rat conceptal homogenates. Biochem Pharmacol 50, 1257-1264.

Deluca HF \& Roberts AB (1969) Pathways of retinoic acid and retinol metabolism. Am J Clin Nutr 22, 945-952.

Eastwood GL (1977) Gastrointestinal epithelial renewal. Gastroenterology 72, 962-975.

Giguere V, Ong ES, Segul P \& Evans RM (1987) Identification of a receptor for the morphogen retinoic acid. Nature 330, 624-629.

Hanson WR (1982) Proliferative and morphological adaptation of the intestine to experimental resection. Scand J Gastroenterol 74 (Suppl.) 11-20.

Herr FM, Wardlaw SA, Kakkad B, Albrecht A, Quick TC \& Ong DE (1993) Intestinal vitamin A metabolism: coordinate distribution of enzymes and CRBP (II). J Lipid Res 34, 1545-1554.

Joseph LW, Deborah AS, Deborah CR \& Marc SL (1997) Retinoic acid stimulates early cellular proliferation in the adapting remnant rat small intestine after partial resection. J Nutr 127, 1297-1303.

Lampen F, Meyer S, Arnhold T \& Nau H (2000) Metabolism of vitamin A and its active metabolite All-trans-retinoic acid in small intestinal enterocytes. J Pharmacol Exp Ther 295, 979-985.

Lintig J \& Vogt K (2004) Vitamin A formation in animals: molecular identification and functional characterization of carotene cleaving enzymes. $J$ Nutr 134, 251S-256S.

Lotan R (1996) Retinoids in cancer prevention. FASEB J 10, 1031-1039.

Lowry OH, Rosebrough NJ, Farr AL \& Randall RJ (1951) Protein measurement with the folin phenol reagent. J Biol Chem 193, 265-275.

Moore T (1930) Vitamin A and carotene. VI. The conversion of carotene to vitamin A in vivo. Biochem J 24, 692-702.

Napoli JL (1999) Interactions of retinoid binding proteins and enzymes in retinoid metabolism. Biochim Biophys Acta 1440, 139-162.
Nau H \& Blanner WJ (eds) (1999) Retinoids. The Biochemical and Molecular Basis of Vitamin A and Retinoid Action. New York: Springer.

Ong DE (1993) Retinoid metabolism during intestinal absorption. $J$ Nutr 123, 351-355.

Parlesak A, Menzl I, Feuchter A, Bode JC \& Bode C (2000) Inhibition of retinol oxidation by ethanol in the rat liver and colon. Gut 47, 825-831.

Petkovich M (1992) Regulation of gene expression by vitamin A; the role of nuclear retinoic acid receptors. Апnи Rev Nutr 12, 443-471.

Rexer BN, Zheng WL \& Ong DE (2001) Retinoic acid biosynthesis by normal human breast epithelium is via aldehyde dehydrogenase 6 , absent in MCF-7 cells. Cancer Res 61, 7065-7070.

Thambidorai D \& Bachhawat BK (1977) Purification and properties of brain alkaline phosphatase. J Neurochem 29, 503-512.

Tomita S, Tsujita M \& Ichikawa Y (1993) Retinal oxidase is identical to aldehyde oxidase. FEBS Lett 336, 272-274.

Wald G (1968) The molecular basis of visual excitation. Nature 219, 800-807.

Wang JL, Swartz-Basile DA, Rubin DC \& Levin MS (1997) Retinoic acid stimulates early cellular proliferation in the adapting remnant rat small intestine after partial resection. J Nutr 127, 1297-1303.

Weiser MM (1973) Intestinal epithelial cell surface membrane glycoprotein synthesis. J Biol Chem 248, 2536-2541.

Wojciech A, Gonzalo I \& Regina P (1999) Metabolism of retinaldehyde and other aldehydes in soluble extracts of human liver and kidney. $J$ Biol Chem 274, 33366-33373.

Wolf G (1984) Multiple functions of vitamin A. Physiol Rev 64, 873-937.

Wong MH, Stappenbeck TS \& Gordon JI (1999) Living and commuting in intestinal crypts. Gastroenterology 116, 208-215. 